\title{
Dr. Rajbhandary, et al, reply
}

To the Editor:

We are pleased that Lemmey and colleagues ${ }^{1}$ applaud our bringing attention to rheumatoid cachexia. We appreciate their clarifications and emendations of our editorial ${ }^{2}$ (which we know they and others will understand had certain publication constraints and was not intended to be a comprehensive review article). We respectfully acknowledge their valuable contributions to our understanding of cachexia in rheumatoid arthritis. We all agree this is an important topic deserving more recognition and attention. We all agree that high intensity resistance training to improve muscle strength in these patients is of value. We all agree that salutary effects of other therapeutic approaches to ameliorate the manifestations of cachexia remain uncertain; we clearly qualified our statements about these. We all agree that rheumatoid cachexia is an important topic deserving of more attention and further study.

ROSY RAJBHANDARY, MD; AZADEH KHEZRI, MD; RICHARD S. PANUSH, MD, Department of Medicine, Saint Barnabas Medical Center, and the University of Medicine and Dentistry of New Jersey - New Jersey Medical School, Livingston, New Jersey, USA. Address correspondence to Dr. R. Panush, Keck School of Medicine, University of Southern California, HMR 711, 2011 Zonal Avenue, Los Angeles, CA 90032,USA.E-mail: panush@usc.edu

\section{REFERENCES}

1. Lemmey AB, Jones J, Maddison PJ. Rheumatoid cachexia: What is it and why is it important? [letter]. J Rheumatol 2011;38:2074.

2. Rajbhandary R, Khezri A, Panush RS. Rheumatoid cachexia: What is it and why is it important? [editorial]. J Rheumatol 2011; 38:406-8.

J Rheumatol 2011;38:9; doi:10.3899/jrheum.110478 